\title{
Research status and development trend of Urea-SCR technology
}

\author{
Zhanfeng $\mathrm{Qi}^{1, \mathrm{a}}$, Shusen $\mathrm{Li}^{1, \mathrm{~b}}$, Xiuli Guo ${ }^{2, \mathrm{~b}}$ and Wuqiang Long ${ }^{3, \mathrm{C}}$ \\ ${ }^{1}$ Northeast Forestry University, Harbin 150040, China \\ ${ }^{2}$ Dalian University, Dalian 116622, China \\ ${ }^{3}$ Dalian University of Technology, Dalian 116024, China \\ asnake_eyes@qq.com, ${ }^{b}$ lishusenzp@126.com, cguoxiuli@dlu.edu.cn, dongwq@dlut.edu.cn
}

Keywords: Diesel; NOx; Emissions control; Urea-SCR

\begin{abstract}
Stringent emissions regulations require further reducing NOx emissions, selective catalytic reduction (SCR) technology is the mainstream technology to remove NOx at euro $\mathrm{V}$ and euro VI stage. First This article introduces the chemical reaction mechanism of Urea-SCR technology that could reduce NOx emissions from diesel engine. Then it points out research actuality of Urea-SCR from the urea storage device, urea supply system, catalystic converter and control unit separately. Finally it analyzed development trend of SCR technology based on research that we have today.
\end{abstract}

\section{Introduction}

Recently, with the aggravation of global atmospheric pollution and increase of awareness for environmental protection, the $\mathrm{NO}_{\mathrm{x}}$ after-treatment technology is paid more and more attention. As the mainstream technology of heavy duty diesel engines to reduce the $\mathrm{NO}_{\mathrm{X}}$, selective catalytic reduction (SCR) technology refers to the reaction of exhaust and $\mathrm{NO}_{\mathrm{X}}$ to $\mathrm{N}_{2}$ by inhibiting the nonselective combustion of reductant under the action of catalyst. The absolute amount of unburned $\mathrm{HC}$ in the exhaust is low, and diesel engines need adding a little more reductant to purify $\mathrm{NO}_{\mathrm{X}}$ since they adopt oxygen-enriched combustion technology. Urea-SCR technology is developed based on the ammonia selective reduction of $\mathrm{NO}_{\mathrm{X}}\left(\mathrm{NH}-{ }_{3}-\mathrm{SCR}\right)$ technology. But as one kind of gas, ammonia is too difficult to move and store. Ammonia is also highly corrosive, prone to leakage, while urea is characterized by non-toxic, clean, odorless, non-flammable, no explosion danger and low corrosive. So we use an aqueous solution of urea instead of ammonia generally in the current, and use the ammonia from urea thermal decomposition to restore the $\mathrm{NO}_{\mathrm{X}}$ of diesel exhaust. Urea - SCR has been used all over the world widely as the most mature post-processing technology of $\mathrm{NO}_{\mathrm{X}}$.

\section{Structure of system and chemical reaction of SCR}

A typical Urea-SCR system includes urea storage device, urea supply system, catalytic converters and control unit.

When SCR is working, the control unit performs the predefined control strategy. Then the urea solution in the storage device is sucked by the supply pump and injected into the exhaust pipe in front of the catalysts through the nozzle of urea supply system. The urea reduces into reductant $\mathrm{NH}_{3}$ by heating, as shown in formula (1). On the surface of the SCR catalyst, the $\mathrm{NO}_{\mathrm{X}}$ is reduced to $\mathrm{N}_{2}$ by $\mathrm{NH}_{3}$, its main formula of reaction as shown in (2) and (3):

$\left(\mathrm{NH}_{3}\right)_{2} \mathrm{CO}_{2}+\mathrm{H}_{2} \mathrm{O} \rightarrow 2 \mathrm{NH}_{3}+\mathrm{CO}_{2}$

$4 \mathrm{NH}_{3}+4 \mathrm{NO}+\mathrm{O}_{2} \rightarrow 4 \mathrm{~N}_{2}+\mathrm{CO}_{2}$

$4 \mathrm{NH}_{3}+2 \mathrm{NO}+2 \mathrm{NO}_{2} \rightarrow 4 \mathrm{~N}_{2}+6 \mathrm{H}_{2} \mathrm{O}$

In high-temperature environment (higher than $300{ }^{\circ} \mathrm{C}$ ), $\mathrm{NO}_{\mathrm{X}}$ in the exhaust gas can quickly react with ammonia $\left(\mathrm{NH}_{3}\right)$ to form $\mathrm{N}_{2}$ and $\mathrm{H}_{2} \mathrm{O}$ under the action of the catalyst. The temperature of diesel engine exhaust is generally in the range of $300 \sim 500{ }^{\circ} \mathrm{C}$, it meets the temperature conditions that $\mathrm{NO}_{\mathrm{X}}$ reduction needs. 


\section{Present status of Urea-SCR technology}

The most ideal working conditions of Urea-SCR system is to ensure a low escape rate of reductant $\mathrm{NH}_{3}$ on the premise of achieving a high conversion of $\mathrm{NO}_{\mathrm{X}}$. To meet these two requirements, we must ensure the following three performance indicators: good level of droplet evaporation and pyrolysis, reasonable space velocity distribution, reasonable concentration distribution of the reductant. SCR supply system should ensure that the liquid droplet can be reacted completely for evaporation and pyrolysis before entering the inside of the catalytic converter carrier. And reasonable space velocity distribution is to ensure that reductant and reactant have plenty of contact and reaction time. Moreover reasonable distribution of reductant is the determinant conditions that avoid excess ammonia coefficient too high or too low. The current studies are going largely around the urea storage device, urea supply system, catalytic converters, control unit and three performance indicators that are mentioned later in this article.

Urea storage device. Urea storage device, which is used for storing the urea solution, mounts transducer, heating device and ventilation device at the top and the screw holes to release the residual liquid at the bottom. Transducer includes temperature sensor and level sensor, which can sense the temperature and height of the urea level.

It consists of two parts to research urea storage device: the stability of solution and the adaptability to the environment. Urea solution is alkaline, the $\mathrm{PH}$ of which is 8.8. And its corrosion for copper, cast iron, solder and aluminum is serious. So we must use special materials such as austenitic steel to make its storage, pipeline transportation and filling. The urea storage device generally uses urea aqueous solution which concentration is $32.5 \%$, the most important reason is the lowest freezing point of the solution $\left(-1{ }^{\circ} \mathrm{C}\right)$. Even if the concentration of the urea aqueous solution is in a semi-frozen state, the solution concentration remains unchanged. Not only that, the concentration of solution can still keep unchanged for a long time in normal storage conditions. So it is suitable for long-term preservation in process of transport or storage. And it also meets the requirement that vehicle is not used for a long time. When the temperature was lower than the $-11{ }^{\circ} \mathrm{C}$, urea solution began to crystallize. So Urea tank has the low temperature heating device.

In addition, there are a lot of alternatives of urea solution, including the solid urea, ammonium salts (such as ammonium carbamate), chloride salts (such as magnesium chloride) storage technologies of ammonia [1-2]. Part of the solution can make the freezing point of urea solution to - $30{ }^{\circ} \mathrm{C}$. However, it still need further study about additional heat source, influence of fuel economy, the response characteristics of the release of $\mathrm{NH}_{3}$ and other issues.

Urea supply system. Urea supply system consists of the following parts: the urea supply unit, the air assist unit, measuring injection system, connecting pipes, all kinds of sensors and heating devices etc.

There are two main types of urea supply unit: one is represented by Grundfos company, another is represented by Bosch company. The first unit uses a stepper motor to drive a constant volume of plunger reciprocating motion and achieves the control of supply by controlling the speed of the motor. The second unit achieves the control of supply by controlling the solenoid valve, which is controlled by a PWM. But it must adopt a urea pump to build a constant pressure in the line before the solenoid valve.Urea supply system is divided into two types: air-assisted and non-air-assisted[2].

Injection system of measurement is an important research domain in Urea - SCR. Its function is that urea solution can be sprayed into the exhaust pipe by fog according to the demand of Urea under the control of the Data Controlled Unit (DCU). Generally this system improves the quality of urea injection through improving nozzle structure and strengthening its atomization characteristics. It also improves the atomization results by improving the pipeline shape, position and angle of the spray. This way can promote the decomposition of urea, and it also can reduce the formation of deposits[3].

There are two methods to the mature technology of decomposing urea into $\mathrm{NH}_{3}$ : pyrolysis and hydrolysis. Currently the SCR of vehicles takes pyrolysis technology. This technology supposes 
that urea pyrolysis and catalytic going at once in an ideal world. The urea solution can be decomposed completely before entering the catalyst, and $\mathrm{NH}_{3}$ mixes with the engine exhaust. But in actual condition, the distance between the urea aqueous solution injection and the catalyst entrance is very short, the decomposition of urea at the entrance is not sufficient. It also cannot guarantee that reductant and exhaust could be mixed uniformity, and it generates other by-products. The test indicates that, a mixture of $\mathrm{NH}_{3}$, $\mathrm{HNCO}$ and urea enters into the catalyst due to the more undecomposed urea at the entrance of catalyst. HNCO has a polymerization with urea to biuret easily at higher temperature(about $150-200^{\circ} \mathrm{C}$ ) because its activity is very high. It may form cyanuric acid and react with $\mathrm{NH}_{3}$ to ammelide, ammeline, melamine and so on[4]. The main component of the sediment is the crystallization of urea when the temperature of exhaust is lower than $150^{\circ} \mathrm{C}$. These deposits may clog the nozzle of urea and the catalyst carrier. It also may affect the activity of catalyst and increase the consumption of urea. These repercussions bring about the difficulty to control the SCR system. Thus the cryogenic sediment of urea is a hot issue of SCR field in the current.

It is common practice to install mixer before the SCR catalyst for promoting the evaporation, decomposition of the urea and the mixture of exhaust. Numerical simulation and experiment show that mixer is helpful to reducing the generation of sediment and improving conversion efficiency of SCR.

Catalysts. Catalyst has three basic parts: the coating, carrier and package. The study of catalyst focuses on the choice of chemical reaction coating, internal carriers of catalyst and the design of muffler.

Coating what consists of water coating and activity components of catalytic is the core of the catalyst. Urea-SCR catalyst bases on vanadium-based catalyst $\left(\mathrm{TOi}_{2}-\mathrm{V}_{2} \mathrm{O}_{5}\right)$ and zeolite catalyst[5]. The advantages of vanadium-based catalyst are high conversion efficiency, high and wide temperature window, good resistance to sulfur and low cost. But the volatilization of vanadium will lead to inactivate when the temperature is higher than $600-800^{\circ} \mathrm{C}[6]$. The temperature from heavy engine to the surface of catalyst cannot reach such a high level, so it is applied to the domestic heavy engine.

The conventional coating application of SCR catalyst also includes catalyst that is used to remove ammonia. This catalyst is named AMOX (Amm on Oxidation catalyst). And it is also be used to remove $\mathrm{NH}_{3}$ that is remained after the main reaction of SCR. Alternative technology is that we installs the after-oxidation catalytic converter after the SCR catalyst. But there are problems with these solutions. Not only may oxidise these solutions from $\mathrm{NH}_{3}$ into $\mathrm{NO}_{\mathrm{X}}$ as to increase pollution and system cost, but also cause waste of urea injection to a certain degree. So we place the before-oxidation catalysts before the SCR catalyst as the pretreatment device of engine exhaust generally.

Carrier is the skeleton part of SCR system, AMOX and coating are coated on the carrier. Most of carrier is a whole which has cylindrical cellular channel. Its basic material can be divided into two categories: metal and ceramic based.

Package for SCR catalyst that is used to connect the carrier with the exhaust pipe is the outer packing of carrier. It can be divided into packages with silencer and without silencer according to the different functions as the outer packing of carrier. It also can be divided into boxes and barrels type package depending on the arrangement of whole vehicle.

Control unit. The control unit of Urea - SCR collects signals from the operation condition of the engine ECU and the sensor of SCR system. It also treats with these signals. And it can calculate the demand for urea according to the strategy of urea injection. At the same time, it takes the signal to the corresponding execution unit and controls the urea injection. In addition, it has the function of fault inspection and diagnosis. Progress in the control unit is mainly reflected in two aspects: software and hardware. The key of hardware is the further study of the sensor, and the key of software is the control strategy of urea injection.

The control strategy of urea injection can be divided into open-loop control and closed-loop control from the structure. The main difference is whether it uses signal of $\mathrm{NH}_{3} \operatorname{sensor(or~} \mathrm{NO}_{\mathrm{X}}$ sensor) 
which is loaded in downstream of SCR for feedback control[7]. SCR open-loop control strategy system doesn't have the ability to correct automatically or compensate. SCR closed-loop control strategy can improve the accuracy of the control and stability, and the response time is shortened. However, there is still a lack of sensor sensitivity and the cost issues, owing to the cross-sensitivity of $\mathrm{NO}_{\mathrm{X}}$ sensor and the immature technology of $\mathrm{NH}_{3}$ sensor. Current solutions include stimulus-response method and adding post-oxidation catalytic converter.

The urea injection control strategies of SCR system can be divided into mapping based on pulse spectrum and model based on calculations from the controller design. The control strategy of model based on calculations is complexity, and it has few applications. The structure design ideas of open-loop urea injection control strategies based on the pulse spectrum is simple, and its development difficulty is low. So there is more widely application in engineering.

SCR system requires fine control of urea to meet the strict emissions standards. However, feedback control and the optimization of control strategy are very difficult because the SCR system involves many aspects.

\section{Conclusion}

In recent years, China increases investment in science and technology for environmental protection. It makes great progress in the overall level of science and technology, and it reaches or approaches international advanced level in some areas. Research Center for Eco-Environmental Sciences, Tsinghua University, the PLA Academy of Military Transportation, China Environmental Science Research Institute and many other domestic research institutes all study for purification technology of diesel exhaust. Dalian University is studying the closed-loop control strategy of SCR based on pulse spectrum. Experiments show that this strategy can improve the catalytic efficiency of SCR, and it also can reduce the difficulty of the SCR system control. So it will achieve more precise feed control. This SCR can open a new direction of diesel engine exhaust gas purification.

Acknowledgments:This paper is supported by the National Natural Science Foundation of China(51306025) and the Fundamental Research Funds for the Central

Universities(2572015AB13).

\section{References}

[1] Fulks G, Fisher G B, Rahmoeller K, et al. 'A Review of Solid Materials as Alternative Ammonia Source for Lean NOx Reduction with SCR', SAE Paper, 2009-01-0907

[2] Johannessen T, Schmidt H, Svagin J, et al. 'Ammonia Storage and Delivery Systems for Automotive $\mathrm{NO}_{\mathrm{x}}$ Aftertreatment ', SAE Paper, 2008-01-1027

[3] Hua L, Zhao Y, Hu J, et al. 'Comparison between Air-assisted and Airless Urea Spray for Diesel SCR System by PDA and CFD’, SAE Paper, 2012-01-1081

[4] Yu Jiao. 'Optimization for SCR system of Heavy Engine Layout Based on STARCD', The Annual Symposium of CDAJ in 2008. 2008-6-9-11

[5] Lundström A, Andersson B, Olsson L. 'Urea Thermolysis Studied under Flow Reactor Conditions Using DSC and FT-IR'， Chem Eng J, 2009, 150(2-3): 544-550

[6] Strots V O, Santhanam S, Adelman B J, et al. Deposit Formation in Urea-SCR Systems [R]. SAE Paper, 2009-01-2780

[7] Dong Hongyi. 'The Experimental Research and Numerical Simulation about the Technology of $\mathrm{NO}_{\mathrm{X}}$ Selective Catalytic Reduction of Diesel Engine’, Beijing: Tsinghua University, 2008 